\title{
Leitthema
}

Gefässchirurgie 2014 • 19:545-548

DOI 10.1007/s00772-014-1348-4

Published online: 20. Oktober 2014

(c) The Author(s) 2014. This article is published

with open access at link.springer.com

\author{
A. Jawien · B. Formankiewicz · T. Derezinski · A. Migdalski · P. Brazis · L. Woda \\ Department of Vascular Surgery and Angiology, University Hospital No.1, \\ Collegium Medicum, University of Nicolai Copernicus, Bydgoszcz
}

\section{Abdominal aortic aneurysm screening program in Poland}

\section{Aim} low the renal arteries with a diameter larger than $50 \%$ of the normal measurement or with a diameter of $3 \mathrm{~cm}$ or more $[1,2]$. The prevalence of AAAs is estimated to be $4-7 \%$ in men aged 65 years and older $[2,3]$ and only $1.3 \%$ in women of the same age [4]. Most AAAs are asymptomatic and are very often diagnosed incidentally during imaging studies performed for other diseases. The rupture of AAAs can also be the first evidence of an imminently life-threatening AAA. Mortality rates associated with rupture of an AAA remain consistently high $(60-80 \%$, [5]). Approximately $50 \%$ of patients die before treatment and later half of those who survived the operation can die in the perioperative and postoperative period. In contrast, elective surgery carries a much lower risk of death (3-6\%); therefore, this is why there was a need to find a way to diagnose the patients with AAA earlier and submit them to elective surgery for lowering the rates of AAA rupture and patient mortality. A single screening for AAAs by means of ultrasound examination of the aorta in men over the age of 65 years is currently highly recommended by several vascular societies. Such screening programs are now officially available in the USA, UK and Sweden [6-8].

In Poland there is so far no national screening for AAA; therefore, it was decided to introduce the first attempt of a screening program for men in one of the Polish provinces of over 2 million inhabitants (• Fig. 1).
The aim of the study was to determine the prevalence of AAA among men aged 60 years and older, undergoing ultrasound examination of the abdominal aorta. Additionally, the following were assessed: (1) relationship of selected risk factors with the presence of AAA, (2) prevalence of AAA in men at the age of 65 years and (3) prevalence of AAA in men aged 6575 years who have ever smoked. Tasks 2 and 3 were taken into consideration because of particular differences between the UK and the USA screening programs for AAA. The assignment to such groups of screened men made it possible to com-

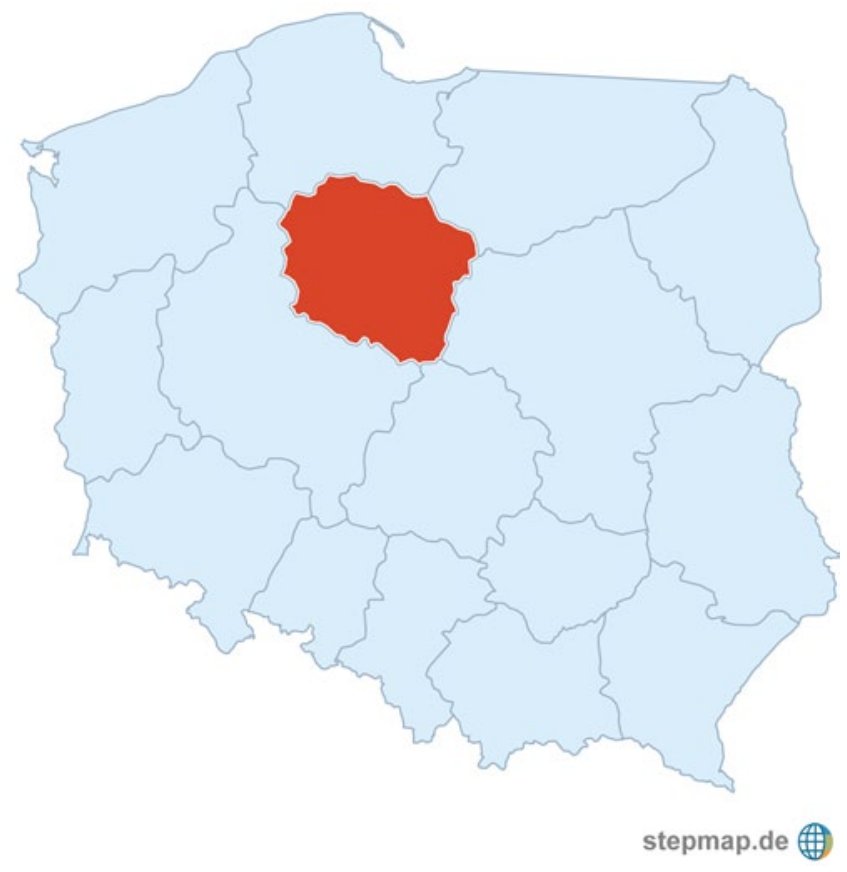

Fig. $1<$ Map of Poland (38 million inhabitants) showing the location of the Kuyavian-Pomeranian Province (2 million inhabitants) pare the data with those available from the UK and the USA.

\section{Material and methods}

The population of men aged 60 years and older was screened by single ultrasonography of the abdomen. The aorta was examined from the renal arteries to the bifurcation and the diameter of the aorta was measured in its largest point. The cut-off value for differentiating between a normal aorta and an aneurysm of the aorta was set at a diameter of $\geq 30 \mathrm{~mm}$. All ultrasonography measurements were performed by physicians in outpatient practices across the Kuyavian-Pomeranian Province. Ad- 
Gefässchirurgie 2014 · 19:545-548 DOI 10.1007/s00772-014-1348-4

( ) The Author(s) 2014. This article is published with open access at link.springer.com

\section{A. Jawien · B. Formankiewicz - T. Derezinski · A. Migdalski · P. Brazis · L. Woda Abdominal aortic aneurysm screening program in Poland}

Abstract

Background. Screening for abdominal aortic aneurysms (AAA) is currently recommended by several vascular societies. In countries where it has been introduced the prevalence of AAAs differed greatly and was mainly related to cigarette smoking. The screening program also had an enormous impact on the decrease of AAA ruptures and reduced mortality rate. These facts have led to the introduction of the first screening program for AAAs in Poland.

Objective. The aim of the study was to determine the prevalence of AAAs among men aged 60 years and older undergoing ultrasound examination of the abdominal aorta. Material and methods. A single ultrasonography of the abdomen was performed to assess the aorta from the renal arteries to the bifurcation and the diameter of the aor- ta was measured at its widest point. The cutoff value for determining an aortic aneurysm was set at a diameter of $\geq 30 \mathrm{~mm}$. All ultrasonography measurements were performed by physicians in outpatient departments throughout the Kuyavian-Pomeranian Province. Additionally, each subject had to fill out a questionnaire with demographic data, smoking habits, existing comorbidities and familial occurrence of AAAs. The study was conducted from October 2009 to November 2011.

Results. The abdominal aorta ultrasound examinations were carried out in 1556 men aged 60 years and older. The prevalence of AAA in the study population was $6.0 \%$ (94 out of 1556). The average age of the men was 69 years (SD 6 years, range 60-92 years). In the study population $55 \%$ of the men smoked or had smoked and 3\% were aware of the presence of AAAs in family members. There were three risk factors significantly associated with the presence of AAAs: age $(p<0.05)$, smoking $(72.3 \%$ vs $53.9 \%, p=0.004)$ and family history of AAAs ( $9.6 \%$ vs $2.7 \%$, $\mathrm{p}=0.017$ ).

Conclusion. The prevalence of AAAs among men in Poland is higher than in other European countries and the USA. The screening program for AAAs is an easy and reliable method for detecting early stages of the disease and risk factors which are the driving forces for the development of AAAs.

\section{Keywords}

Rupture $\cdot$ Screening $\cdot$ Ultrasonography . Prevention · Risk factors

\section{Screeningprogramm auf abdominale Aortenaneurysmen in Polen}

\section{Zusammenfassung}

Hintergrund. Von mehreren gefäßmedizinischen Fachgesellschaften werden derzeit Screeningprogramme für ein abdominales Aortenaneurysma (AAA) empfohlen. In den Ländern, in denen sie schon implementiert wurden, zeigten sich erhebliche Prävalenzunterschiede, AAA wurden v. a. mit Zigarettenrauchen in Verbindung gebracht. Ferner hatte das Screeningprogramm enormen Einfluss auf sinkende Rupturraten und geringere Mortalitätsraten. Diese Tatsachen haben zur Einführung des ersten Screeningprogramms für AAA in Polen geführt.

Ziel. Ziel der Studie war die Bestimmung der AAA-Prävalenz bei Männern im Alter von $\geq 60$ Jahren mittels einer sonographischen Untersuchung der Aorta abdominalis. Material und Methoden. Zur Untersuchung der Aorta zwischen Aa. renales und Bifurkation sowie zur Bestimmung des größten aor- talen Durchmessers wurde eine einzelne abdominale Ultraschalluntersuchung durchgeführt. Der Cut-off-Wert zur Bestimmung eines AAA wurde bei einem Durchmesser von $\geq 30 \mathrm{~mm}$ gesetzt. Alle sonographischen Messungen erfolgten durch Ärzte in Ambulanzen der gesamten Provinz Kujawsko-Pomorskie. Zusätzlich war von jedem Probanden ein Fragebogen zu demographischen Details, Rauchgewohnheiten, Komorbidität und AAAbezogener Familienanamnese auszufüllen. Durchgeführt wurde die Studie von 10/2009 bis $11 / 2011$.

Ergebnisse. Ultraschalluntersuchungen der Aorta abdominalis wurden bei 1556 Männern im Alter von $\geq 60$ Jahren durchgeführt. Die AAA-Prävalenz im Studienkollektiv lag bei $6 \%$ (94 von 1556), das Durchschnittsalter betrug 69 Jahre (60-92, Standardabweichung 6 Jahre). Zum Zeitpunkt der Studie oder früher waren 55\% des Kollektivs Raucher, eine AAA bei Familienmitgliedern war in 3\% der Fälle bekannt. Drei Risikofaktoren waren statistisch signifikant assoziiert mit einem AAA: Alter $(p<0,05)$, Nikotinkonsum $(72,3$ vs. $53,9 \%$, $p=0,004)$ und eine für AAA positive Familienanamnese (9,6 vs. $2,7 \%, p=0,017)$.

Schlussfolgerung. Die AAA-Prävalenz unter in Polen lebenden Männern ist höher als die Prävalenz bei Männern anderer europäischer Länder und aus den USA. Das AAA-Screeningprogramm ist eine einfache, verlässliche Methode zur Detektion sowohl früher Stadien der Erkrankung als auch der für die Entwicklung eines AAA wesentlichen Risikofaktoren.

\section{Schlüsselwörter}

Ruptur · Screening · Ultraschall · Prävention · Risikofaktoren ditionally, each subject had to fill out the questionnaire with demographic data, smoking habits, existing comorbidities and familial occurrence of AAA. The study was conducted from October 2009 to November 2011. Statistical analysis of the data was performed using the software STATISTICA 9 (StatSoft 200, Krakow, Poland). A p-value $\leq 0.005$ was considered as statistically significant.

\section{Results}

Over the period of 3 years the abdominal aortic ultrasound examinations were carried out in 1556 men aged 60 years and older. The prevalence of AAA in the study population was $6.0 \%$ (94 out of 1556 ; - Tab. 1). The average age of the men was 69 years (SD 6 years, range 60-92 years). In the study population $55 \%$ of the men smoked or had ever smoked and 3\% were aware of the presence of AAA in family members. Of the AAAs detected by the screening program $75 \%$ were small (less than $44 \mathrm{~mm}$ ) and observational follow-up of ultrasound was required once a year. The AAAs detected with a diameter between $45 \mathrm{~mm}$ and $54 \mathrm{~mm}$ were observed in 13 patients (14\% of AAAs) and AAAs with a diameter equal to or exceed- 
Tab. 1 Prevalence of abdominal aortic aneurysms $(A A A)$ in each year of performing screening

\begin{tabular}{|llll}
\hline $\begin{array}{l}\text { Year of re- } \\
\text { cruitment }\end{array}$ & $\begin{array}{l}\text { Number of } \\
\text { screened men } \\
\text { (n) }\end{array}$ & $\begin{array}{l}\text { AAA } \\
\text { (n) }\end{array}$ & $\begin{array}{l}\text { AAA } \\
\text { (\%) }\end{array}$ \\
\hline 2009 & 496 & 37 & 7.5 \\
\hline 2010 & 563 & 25 & 4.4 \\
\hline 2011 & 497 & 32 & 6.4 \\
\hline Total & 1556 & 94 & 6.0 \\
\hline
\end{tabular}

Tab. 2 Distribution of the identified abdominal aortic aneurysms $(A A A)$ divided into groups according to maximum diameter

\begin{tabular}{|lll}
\hline $\begin{array}{l}\text { AAA maximum } \\
\text { diameter }(\mathrm{mm})\end{array}$ & $\begin{array}{l}\text { Patients } \\
\text { with AAA } \\
\text { (n) }\end{array}$ & AAA (\%) \\
\hline $30-44$ & 71 & 75 \\
\hline $45-54$ & 13 & 14 \\
\hline 55 and more & 10 & 11 \\
\hline Total & 94 & 100 \\
\hline
\end{tabular}

Tab. 3 Logistic regression analysis of risk factors associated with the presence of abdominal aortic aneurysm (AAA)

\begin{tabular}{|c|c|c|c|c|c|}
\hline Risk factor & $\begin{array}{l}\text { AAA } \\
n=94\end{array}$ & $\begin{array}{l}\text { Normal aorta } \\
n=1462\end{array}$ & P-value & Odds ratio & $\begin{array}{l}95 \% \text { Confidence } \\
\text { interval }\end{array}$ \\
\hline Age (years $\pm S D$ ) & $72.1 \pm 6.6$ & $68.9 \pm 5.9$ & 0.05 & 1.08 & $1.04-1.11$ \\
\hline Smoking (\%) & $68(72.3 \%)$ & 789 (53.9\%) & 0.004 & 2.02 & $1.26-3.25$ \\
\hline Family history (\%) & $9(9.6 \%)$ & $40(2.7 \%)$ & 0.017 & 2.60 & $1.18-5.68$ \\
\hline
\end{tabular}

ing $55 \mathrm{~mm}$ were diagnosed in 10 patients (11\%; - Tab. 2).

Risk factors associated with AAA were analyzed and the study sample could be divided into two groups: group I men with AAA ( $n=94)$ and group II men with a normal aorta $(n=1462)$. There were three risk factors significantly associated with the presence of AAA: age $(\mathrm{p}<0.05)$, smoking (72.3\% versus $53.9 \%, \mathrm{p}=0.004)$ and family history of AAA (9.6\% versus $2.7 \%$, $\mathrm{p}=0.017$; Tab. 3).

The additional task was undertaken to determine the prevalence of AAA in patients who met the criteria for inclusion of AAA screening programs in the UK and the USA. In the UK the AAA screening program includes only men aged 65 years. The number of Polish men screened at the age of 65 years was 224 during the 3 year study and AAAs were found in 9 which accounts for a prevalence of $4 \%$. This percentage is equal to that of the $\mathrm{Na}$ tional Health Service Abdominal Aortic Aneurysm Screening Program in the UK [9]. In contrast, in the USA a single ultrasound examination of the aorta is offered to men between 65 and 75 years of age who have ever smoked. In the Polish population of men screened by using US criteria, a group of 41 AAAs out of 555 men was identified which accounts for a prevalence of $7.4 \%$. This percentage is higher than that of the Screen for Abdominal Aortic Aneurysms Very Efficiently (SAAAVE) Act (5.1\%) in the USA [10].

\section{Discussion}

According to the recent European Society for Vascular Surgery (ESVS) guidefer the best evidence regarding the prevalence of AAA. This evidence is mainly based on four randomized trials which showed the reduced risk of AAA rupture in men when ultrasound screening was performed [2]. The prevalence of AAAs differs from country to country and depends on the type of screening implemented and magnitude of risk factors, such as smoking present in the screened population. The best organized screening program for AAA is currently run in the UK. It has recently been published that the propensity of the prevalence rate of AAA in the UK is on the decrease from the previous rate of $4 \%$ to the current $1.7 \%$ [11]. Very similar data were also obtained from the screening program in Sweden [12].

In a country like Poland, where the smoking rate among men is still very high and diet is not always properly considered, the higher prevalence of AAA should not be a surprise. The overall results with a $6 \%$ prevalence rate of AAA correspond well with the previous UK data published in the 1990s and American data; however, screening programs for AAA in southern European countries (e.g. Italy, Spain and Portugal) have demonstrated a very similar rate of prevalence of AAA in men despite a Mediterranean diet. This has lines, population screening studies of- led the European guidelines to the statement that the screening of older men for AAA should be recommended in regions where the prevalence in the population is $4 \%$ or higher because this will reduce aneurysm-related mortality by almost half within 4 years of screening, principally by reducing the incidence of aneurysm rupture [2]. The final effect of this preliminary study was the introduction in 2011 of the Kuyavian-Pomeranian AAA screening program [13]. This program is on-going and criteria for AAA screening, accepted by local authorities are similar to those of the UK, with males of age 65 years who have ever smoked. The preliminary results of last 2 years of this program (2012-2013) revealed the prevalence rate of AAA of $5.3 \%$. The national program of AAA screening is going to be launched in Poland in 2015. The final inclusion criteria are still to be discussed.

\section{Conclusion}

- The prevalence of AAA among men in Poland is higher than in other European countries and the USA. A possible explanation for this can be found in the high rate of smoking and very fatty diet in the Polish population.

- To organize a well-defined screening program for AAA requires a lot of effort and very good relations with general practitioners who have access to demographic and medical records of people living in the community.

- The use of media for advertising the AAA screening program has an enormous impact on the compliance rate.

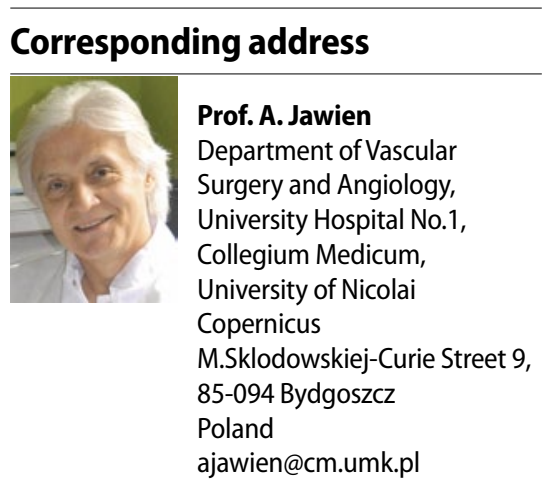




\section{Compliance with ethical guidelines}

Conflict of interest. A. Jawien, B. Formankiewicz, T. Derezinski, A. Migdalski, P. Brazis and L. Woda state that there are no conflicts of interest.

All studies on humans described in the present manuscript were carried out with the approval of the responsible ethics committee and in accordance with national law and the Helsinki Declaration of 1975 (in its current, revised form). Informed consent was obtained from all patients included in studies.

\section{Open Access}

This article is distributed under the terms of the Creative Commons Attribution License which permits any use, distribution, and reproduction in any medium, provided the original author(s) and the source are credited.

\section{References}

1. Johnston KW, Rutherford RB, Tilson MD et al (1991) Suggested standards for reporting on arterial aneurysms. Subcommittee on Reporting Standards for Arterial Aneurysms, Ad Hoc Committee on Reporting Standards, Society for Vascular Surgery and North American Chapter, International Society for Cardiovascular Surgery. J Vasc Surg 13:452-458

2. Moll FL, Powell JT, Fraedrich G et al (2011) Management of abdominal aortic aneurysms. Clinical practice guidelines of the European Society for Vascular Surgery. Eur J Vasc Endovasc Surg 41:S1S58

3. Vardulaki KA, Walker NM, Couto E et al (2002) Late results concerning feasibility and compliance from a randomized trial of ultrasonographic screening for abdominal aortic aneurysm. Br J Surg 89:861864

4. Scott RA, Bridgewater SG, Ashton HA (2002) Randomized clinical trial of screening for abdominal aortic aneurysm in women. Br J Surg 89:283-285

5. Kniemeyer HW, Kessler T, Reber PU et al (2000) Treatment of ruptured abdominal aortic aneurysm, a permanent challenge or a waste of resources? Prediction of outcome using a multi-organ-dysfunction score. Eur J Vasc Endovasc Surg 19:190-196

6. Earnshaw JJ (2011) Doubts and dilemmas over abdominal aortic aneurysm. Br J Surg 98:607-608
7. Lindholt JS, Norman PE (2011) Meta-analysis of postoperative mortality after elective repair of abdominal aortic aneurysms detected by screening. Br J Surg 98:619-622

8. Wilmink AB, Forshaw M, Quick CR et al (2002) ACcuracy of serial screening for abdominal aortic aneurysms by ultrasound. J Med Screen 9:125-127

9. National Health Service Abdominal Aortic Aneurysm Screening Program. http://www.aaa.screening.nhs.uk

10. Lee ES, Pickett E, Hedayati N et al (2009) Implementation of an aortic screening program in clinical practice: implications for the Screen for Abdominal Aortic Aneurysms Very Efficiently (SAAAVE) Act. J Vasc Surg 49(5):1107-1111

11. Conway AM, Malkawi AH, Hinchliffe RJ et al (2012) First-year results of a national abdominal aortic aneurysm screening programme in a single centre. Br J Surg 99:73-77

12. Svensjö S, Björck M, Gürtelschmid M et al (2011) Low prevalence of abdominal aortic aneurysm among 65-year-old Swedish men indicates a change in the epidemiology of the disease. Circulation 124(10):1118-1123

13. Jawien A, Formankiewicz B, Derezinski T et al (2012) Preliminary results from the first Polish screening program for abdominal aortic aneurysm in the Kuyavian-Pomeranian Province. Acta Angiol 18:9-17

\section{Hier steht eine Anzeige.}

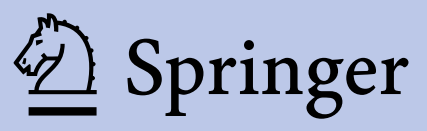

